\title{
PENGGUNAAN MEDIA TEKNOLOGI WATCH DALAM PEMBELAJARAN MATEMATIKA DI SMA KRISTEN IRENE MANADO
}

\author{
ALRI MARASUT \\ 081356095515 \\ alri.marasut@yahoo.com \\ Jurusan Matematika FMIPA, Universitas Negeri Manado
}

\begin{abstract}
Abstrak. Penelitian ini bertujuan mempelajari bagaimana hasil belajar siswa dalam pembelajaran matematika menggunakan media teknologi watch, dibandingkan dengan pembelajaran ekspositori. Rancangan penelitian yang digunakan adalah rancangan eksperimen dan kontrol grup pretes- posttes yang dikenakan pada subyek penelitian, terdiri dari 21 siswa kelompok eksperimen dan 20 siswa kelompok kontrol yang dipilih secara acak dari 41 siswa Kelas X SMA Kristen Irene Manado. Hasil penelitian menunjukkan rata-rata hasil belajar kelompok siswa yang mengikuti pembelajaran matematika dengan menggunakan media teknologi watch lebih tinggi dibandingkan dengan kelompok siswa yang mengikuti pembelajaran ekspositori untuk semua materi pembelajaran yang diprogramkan dalam penelitian ini.
\end{abstract}

Kata kunci: hasil belajar, pembelajaran matematika, media teknologi watch

\begin{abstract}
This research aims to study how the learning outcomes of students in learning mathematics using technology media watch, compared with expository teaching. The design of the study is the design of experimental and control group pretest-posttest imposed on the subject of study, consisting of 21 students of the experimental group and control group of 20 students randomly selected 41 students of Class X Manado Irene Christian High School. The results showed an average group of students learning outcomes that follow mathematics learning using technology media watch group is higher than the students in the expository teaching to all learning materials are programmed in this study.
\end{abstract}

Key words: learning outcomes, learning math, technology media watch

\section{PENDAHULUAN}

Dengan masuknya materi Teknologi Informasi dan Komunikasi (TIK) dalam kurikulum baru Sekolah Menegah Atas, maka peranan komputer sebagai salah satu komponen utama dalam TIK mempunyai posisi yang sangat penting sebagai salah satu media pembelajaran. Kualitas pembelajaran matematika pada jenjang pendidikan dasar dan menengah pada dasarnya masih memprihatinkan. Orang tua siswa mengeluh karena rendahnya nilai matematika dari anak-anak mereka pada setiap ujian semester maupun ujian akhir. Dapat dipahami bahwa tidak banyak siswa yang mempunyai bakat dan minat dalam matematika, tetapi paling tidak mereka dapat dimotivasi, untuk belajar matematika secara bertahap sesuai potensi masing-masing. Demikian pula masih ada guru matematika yang belum terampil merancang strategi pembelajaran matematika yang melibatkan media yang sesuai dengan keragaman dan kesiapan siswa sehingga hasil belajar siswa 
dapat ditingkatkan. Persoalannya sekarang adalah bagaimana mendorong guru matematika untuk merancang media pembelajaran berbasis komputer

Penelitian ini bertujuan merancang pembelajaran matematika dengan media technology watch dan diharapkan siswa termotivasi dan menjadi aktif dalam belajar sehingga hasil capai belajarnya meningkat.

\section{TINJAUAN PUSTAKA}

\section{Media Pembelajaran Dengan Technology Watch}

Technologi watch pada dasarnya merupakan aplikasi teknologi informasi dan komunikasi yang berbasis internet. Dalam era globalisasi, telah terjadi kemajuan pesat di mana ilmu pengetahuan dan teknologi (IPTEK) berkembang dengan cepat. Hal ini membawa implikasi yang sangat besar dalam bidang pendidikan. Informasi tentang kemajuan IPTEK segera dapat diakses kapan saja dan di mana saja secara cepat karena sebagaimana ditegaskan oleh Glenn dan Gordon (2001) bahwa internet sebagai alat globalisasi, harus digunakan untuk merubah pola pikir manusia dalam rangka meningkatkan kondisi sosial. Dalam pendidikan, ini merupakan strategi dasar untuk menghadapi tantangan global terutama untuk mengidentifikasi sarana pendidikan, materi pembelajaran, kurikulum, strategi pembelajaran dan distribusi media untuk mengantisipasi percepatan belajar di sekolah dalam menghadapi pendidikan global.

Gaynor (2005) menjelaskan TechWatch anticipates developments in information and communication technologies that might have high impact on the core business of further and education (teaching and learning) in five to ten years' time.. TechWatch also maintains information resources on specific technologies and standards.

Technology and Standards Watch activities:

- Identify and track developments in Communications and Information

Technology, and in Standards, which are critical to Higher and Further Education

- Commission work from experts from the community or beyond in the form of reports, briefings and other materials, on these technologies and standards, their development and the implications for HE/FE

- Disseminate information to the community on technologies and standards and their developments and implications

- With the Development Director for Systems and Technology, assist JISC to ensure that it is aware of and makes the most effective use of information on emerging technologies and standards

Media technology watch dalam pendidikan, telah dikembangkan secara meluas antara lainnya oleh Dou (2005) yang berasumsi bahwa dalam globalisasi, pengetahuan tak dapat diperoleh seseorang begitu saja tanpa ada visi yang realistis dengan strategi yang kreatif dan kompetitif dalam pengambilan kebijakan untuk mencapai tujuan. Untuk itu, dalam pendidikan diperlukan suatu langkah kreatif dan kompetitif dengan dimulai dari kerjasama dalam mengakses Iptek melalui internet (database dan paten).

Penggunaan media technology watch dalam pembelajaran matematika, berbasis internet dan tentunya melibatkan komputer dan perangkat lainnya yang terkait. Pertama, penyajian materi pelajaran (terbatas) dilakukan dengan power point atau dengan maple, dan pengembangannya akan diakses oleh para siswa melalui web. Tugas-tugas dapat diakses oleh siswa melalui blog guru yang bersangkutan.

Collins \& Nichol (2006) merumuskan enam langkah strategis pembelajaran langsung yang menggunakan media tchnology watch yakni;

1) Motivating Your Mind (memotivasi pikiran): Pembelajaran harus dimulai dengan memotivasi pikiran siswa agar mereka mempunyai keinginan untuk memperoleh keterampilan atau pengetahuan baru (visi). 
2) Acquiring the facts (menyerap fakta/konsep): Pembelajaran berlangsung melalui proses mengumpulkan, menjaring dan menyerap fakta-fakta dasar subjek pelajaran melalui berbagai media (data).

3) Searching out the meaning (menyelidiki makna): Pembelajaran menjadi bermakna (meaningful) bila fakta-fakta dasar subyek pelajaran yang dieksplorasi dari berbagai sumber dalam kehidupan nyata, terinternalisasikan menjadi makna (informasi).

4) Triggering the Memory (memicu memori): Pembelajaran tidak semata-mata menghapal fakta dan informasi subyek pelajaran, tapi melalui latihan menganalisis berulang-ulang dengan memicu ingatan akan terpatri dalam memori jangka panjang sehingga menghasilkan informasi strategis.

5) Exhibiting what you know (memamerkan apa yang anda ketahui): Pembelajaran menjadi menarik dengan melatih siswa mempresentasikan pengetahuan yang sudah diserapnya di dalam kelompok kecil, di depan kelas, diforum diskusi ilmiah ataupun mengajarkan kepada temanya yang belum memahami latihan presentasi pemecahan masalah atau hasil penyelidikan akan memicu pengembangan kecerdasan siswa (Intelijen).

6) Reflecting how you've learned (merefleksikan bagaimana anda belajar): Pengalaman belajar siswa akhirnya direfleksikan melalui ujian. Hasilnya akan berupa koreksi atau perbaikan tentang bagaimana belajar untuk belajar (kebijakan).

Hasil penelitian terkait yang relevan pada beberapa sekolah di Inggris, Colin dan Nicholl (2006) melaporkan bahwa capaian siswa dalam pembelajaran bahasa, seni dan matematika dengan melibatkan media komputer dan internet, meningkat dengan tajam karena mereka dilatih dengan cara belajar cepat dengan mengoptimalkan delapan potensi kecerdasan siswa yakni: kecerdasan bahasa, kecerdasan logika-matematika, kecerdasan antar pribadi, kecerdasan emosional, kecerdasan intra pribadi, kecerdasan kinestetik, kecerdasan visual-spasial dan kecerdasan musical. Secara rata-rata, siswa mengingat subyek pelajaran:20\% dari yang dibaca, 30\% dari yang didengar, $40 \%$ dari yang dilihat, $50 \%$ dari yang dikatakan, $60 \%$ dari yang dikerjakan, $90 \%$ dari yang dilihat, didengar, dikatakan dan dikerjakan sekaligus.

Ebbut dan Sraker (2007), klasifikasi materi pembelajaran matematika pada semua jenjang pendidikan meliputi: fakta, pengertian dan konsep, keterampilan penalaran, keterampilan algoritmik, keterampilan menyelesaikan masalah matematika, dan keterampilan melakukan penyelidikan. Sedangkan kompetensi dasar merupakan kompetensi minimal atau memadai yang seharusnya dicapai setelah siswa menyelesaikan sesuatu pengalaman belajar materi pokok matematika. Selanjutnya, materi pokok merupakan konsep, pokok bahasan, topik atau tema yang dipilih sebagai bahan pembelajaran yang dirumuskan secara umum agar guru dapat memberikan penekanan atau fokus pembelajaran secara fleksibel dan dinamis sesuai kondisi dan kebutuhan sekolah.

Ever and Barrett (2008) mengemukakan bahwa sumber dari percepatan belajar matematika adalah berpikir kreatif untuk mengembangkan informasi bahan pelajaran, mengkaji makna konsep dari berbagai sumber seperti buku, jurnal, melalui perpustakaan, laboratorium atau internet. Tugas guru adalah sebagai fasilitator, membantu dan memotivasi siswa untuk belajar. Selanjutnya, guru perlu menyediakan waktu untuk membimbing siswa dalam memecahkan masalah matematika sesuai persepsi pengalaman masing-masing siswa yang oleh Rowlins (2008) disebut bimbingan untuk berkompetisi dalam percepatan belajar memecahkan soal matematika. 


\section{METODE}

Penelitian ini merupakan studi eksperimen penggunaan media teknology watch dalam pembelajaran matematika. Subyek penelitian dipilih siswa Kelas I SMA Kristen Irene Manado tahun pelajaran 2009/2010 yang terdiri dari 41 siswa. Karena memungkinkan pembagian kelompok, maka subyek dikelompokkan atas dua kelompok A dan B. Pemilihan siswa ke dalam dua kelompok tersebut dilakukan secara acak. Subyek kelompok A terdiri dari 21 siswa dan kelompok B terdiri dari 20 siswa Rancangan yang digunakan dalam penelitian ini adalah rancangan eksperimen Control group pretestposttest design Langkah-langkah yang ditempuh dalam pelaksanaan penelitian eksperimen ini adalah Tahap pertama, memberikan pelatihan pada tenaga pengajar (seorang guru matematika dan seorang mahasisw), untuk mengembangkan silabus matematika dan materi pelajaran, lembar kerja siswa, media dan alat bantu mengajar yang diperlukan. Selanjutnya, memberikan tes awal berbentuk uraian untuk siswa kelompok A dan B. Menurut Susanti (2003), dalam aspek penilaian hasil belajar, bentuk tes obyektif mengukur level kognitif yang rendah sehingga mendorong siswa untuk belajar secara memorisasi. Sebaliknya, tes esai mengukur level kognitif yang lebih kompleks. TIMMS (1999) menegaskan bahwa jika penilaian itu ditujukan pada pemahaman dan penguasaan materi pelajaran dalam satu periode waktu tertentu, maka tes uraian cocok untuk mengukur hasil belajar siswa. Dari hasil pengukuran ini dapat dilihat capaian mereka secara individual dalam pembelajaran yang dirancang oleh guru Dalam pelaksanaan eksperimen pembelajaran matematika dengan menggunakan technology watch dikenakan pada siswa kelompok A dan pembelajaran matematika dengan tidak menggunakan technology wacth pada siswa kelompok B sebagai kontrol.Pelaksanaannya dilakukan oleh dosen, guru dan mahasiswa secara bergantian pada dua kelas yang berbeda secara bersamaan. Materi pelajaran matematika meliputi empat topik utama yakni: Aritmetika, Aljabar, Geometri dan Trigonometri yang disajikan selama 90 jam pertemuan (1 jam pertemuan $=45$ menit) Melaksanakan tes akhir yang setara dengan tes awal untuk siswa kelompok A dan B. Replikasi pelaksanaan tes awal dan tes akhir dilakukan tiga kali masing-masing untuk topik: Aritmetika, Aljabar, dan Geometri/Trigonometri.

Untuk menjamin validitas penelitian ini, situasi dan kondisi pembelajaran pada kelompok A dan B tetap dipertahankan sebagaimana biasanya, maksudnya siswa tidak dikondisikan sedemikian rupa dan ini dijamin oleh pengajar dalam eksperimen ini adalah guru matematika pada sekolah yang bersangkutan. Data tes awal sebelum perlakuan dan tes akhir sesudah perlakuan masing-masing telah dianalisis dengan uji perbedaan dua rata-rata. Statistik uji $T$ digunakan untuk menguji hipotesis nol dengan alternatinya yakni $H_{0}: \mu_{A}=\mu_{B}$ dan $H_{1}: \mu_{A}>\mu_{B}$

\section{HASIL DAN PEMBAHASAN}

Hasil eksperimen dalam pembelajaran matematika di SMA Kristen Kota Manado, secara umum menunjukkan adanya pengaruh positif yang nyata penggunaan media technology watch terhadap peningkatan hasil capai belajar matematika dari para siswa. Hal ini ditunjukkan oleh rata-rata hasil capai belajar kelompok siswa untuk seluruh materi pembelajaran pada kelas eksperimen lebih tinggi dari rata-rata hasil capai belajar kelompok siswa pada kelas kontrol. Secara parsial, rata-rata hasil capai belajar untuk topik pembelajaran Aljabar dan Arithmatika dari kelompok siswa pada kelas eksperimen lebih tinggi dari kelas kontrol. Sedangkan untuk topik pembelajaran Geometri/Trigonometri, tidak menunjukkan perbedaan yang nyata antara kelompok siswa pada kelas kontrol dan kelas eksperimen. Dari hasil tes akhir, nampak bahwa kelompok siswa pada kelas eksperimen dan kelas kontrol sama-sama mengalami kesulitan dalam menyelesaikan soal -soal tergolong sulit yang memerlukan penerapan konsep dan prinsip 
sesuai konteks masalahnya. Walaupun dalam pelaksanaan tes akhir dilakukan pengawasan secara ketat, tapi tidak tertutup kemungkinan siswa-siswa pada kelas kontrol mengambil kesempatan menyontek dengan berbagai cara pada saat guru pengawas lengah.

Keunggulan dari penggunaan medi technology watch dalam penelitian ini menunjukkan bahwa pembelajaran tidak sekedar ceramah, diskusi, tanya jawab dan pemberian tugas rumah, tetapi dilakukan dengan pembelajaran materi melalui power point dan dengan metode dan teknik pembelajaran yang bervariasi seperti pemecahan masalah secara individual atau kerja sama dalam kelompok, kajian makna konsep dan prinsip secara empiris dari berbagai melalui berbagai media terutama internet dan pelaporannya, demonstrasi, penemuan terbimbing dan penyampaian gagasan melalui peta konsep. Proses pembelajaran selalu diarahkan untuk memotivasi siswa, menyegarkan apersepsi, kerja sama dalam diskusi, mendorong siswa agar berpikir, mengarahkan perhatian siswa, menggalakkan penyelidikan, mendiagnosa dan memeriksa tanggapan siswa sehingga siswa belajar bagaimana belajar. Ini juga ditunjang oleh adanya media komputer dan internet yang disediakan oleh Yayasan IRENE Manado sebagai pemilik sekolah ini.

Kelemahannya, siswa-siswa pada sekolah di mana eksperimen ini diadakan masih terbiasa dengan proses pembelajaran dengar, catat dan tugas rumah. Untuk menggunakan media technology watch sesuai rencana pembelajaran yang sudah disusun, ada beberapa kendala antara lainnya: kondisi perpustakaan sekolah yang kurang memadai, media pembelajaran seperti Over Head Projector (OHP) dan LCD hanya tersedia satu unit. Selain itu, guru matematika belum terampil merancang dan menggunakan power point dalam pembelajaran. Berdasarkan pada hasil yang dicapai dalam penelitian ini beserta keunggulan dan kelemahannya, maka pada dasarnya penggunaan media technology watch berbasis internet dalam pembelajaran matematika dapat memicu motivasi siswa menjadi proaktif untuk belajar bagaimana belajar matematika sehingga dapat dikembangkan pada konteks pembelajaran lainnya.

\section{PENUTUP}

\section{Kesimpulan}

Penelitian ini menyimpulkan bahwa terdapat pengaruh positif penggunaan technology watch dalam pembelajaran matematika terhadap peningkatan hasil capai belajar siswa Kelas I SMA Kristen Irene Manado. Hasil kajian tentang pengaruh perlakuan terhadap skor tes akhir yang dimurnikan dari skor tes awal dalam pembelajaran materi Arithmatika dan Aljabar, menunjukkan rata-rata hasil capai belajar siswa dari kelompok eksperimen lebih tinggi dari kelompok kontrol. Sedangkan pada pembelajaran Geometri/Trigonometri, tidak terdapat perbedaan yang nyata. Hal ini diduga sebagai akibat dari tingkat kesukaran soal tes akhir berbentuk uraian yang tergolong cukup sulit.

Proses pembelajaran matematika selama pelaksanaan eksperimen dengan penggunaan media technology watch ternyata telah memberikan pengalaman belajar yang unik bagi siswa karena mereka dibimbing untuk proaktif dalam proses belajar melalui serangkaian kegiatan: memotivasi pikiran, menyerap informasi , menyelidiki makna, memicu ingatan, memamerkan apa yang dipelajari dan refleksi belajar bagaimana belajar.

Disarankan pengembangan media technology watch dalam pembelajaran topik matematika lainnya pada berbagai jenjang pendidikan. Penggunaannya harus sedemikian rupa sehingga pembelajaran yang dirancang dapat memotivasi siswa untuk belajar bagaimana belajar. 


\section{Saran}

Berdasarkan pada hasil yang dicapai dalam penelitian ini beserta keunggulan dan kelemahannya, maka pada dasarnya penggunaan media technology watch dalam pembelajaran matematika dapat memicu motivasi siswa menjadi proaktif untuk belajar bagaimana belajar matematika sehingga dapat dikembangkan pada konteks pembelajaran lainnya.

Implementasinya, dapat dilaksanakan pada berbagai kondisi sekolah termasuk sekolah swasta dengan kondisi siswa yang kemampuannya tergolong sedang atau rendah. Yang perlu dipersiapkan adalah guru matematika yang memiliki kompetensi profesional ingin mengembangkan kemampuannya, menyukai tantangan terutama menghadapi siswa yang kurang mampu, dan penuh perhatian terhadap pengembangan pembelajaran matematika di sekolah.

\section{UCAPAN TERIMA KASIH}

Kepada Kepala SMA Kristen Irene Manado yang telah memberikan kesempatan kepada penulis melakukan penelitian ini saya mengucapkan terima kasih.

Tuhan memberkati.

\section{DAFTAR PUSTAKA}

Cincia, B. 2000. Mathematics in and Out of School: Exemplification From an Activity in Primary School. http://www.nku.edu/bonottopbyd.htm

Collins, R., \& Nicholl, M. J. 2006. Accelerated learning: strategies for survival and success. Journal of Accelerated Learning and Teaching (22), 1-33. http://TEC.carndan.rutgers.Edu/JALT

Dou, H., Dou, M, J., and Manullang, S. 2003. Competitive Intelligence: Technology Watch and Regional Development. MUC Publishing. http://www.chercheur.hd13vl/

Ever \& Barrett. 2008. Mathematics Power Learning Instant Master Teacher. http://www.profb.com/

Ebbutt, S. \& Straker, A. 2007. Children and Mathematics: Mathematics in Primary School. Collins Educational. http://www.profb.com/

Gaynor, H. 2005. Technology Watch. http://www.jiscmail.ac.uk/cgibin/webadmin?A0=JISC-TSW

Glenn, J. C., \& Gordon, T. J. 2001. The Millennium Project 2001, State of the Future. Washington D.C: American Council for the United Nations University.

Rowlins, P. 2008. Students perceptions of their experiences from within acceleration programs in mathematics. Australian Senior Mathematics Journal 18(1), 42-51.

Susanti, R. 2003. Evaluasi pembelajaran di sekolah. Teknodik 12(7), 3-6. http://www.pustekom.go.id/

TIMSS. 1999. International Students Achievement in Mathematics. http://timss.bc.edu/timss 1999i/pdf/t99imath01.pdf 


\section{DAFTAR LAMPIRAN}

Tabel Lamp. 1. Data Hasil Pre-test dan Post-test Materi Aritmetika

\begin{tabular}{|c|c|c|c|c|c|c|c|}
\hline \multirow{2}{*}{ No. } & \multicolumn{3}{|c|}{ KELOMPOK A } & \multirow{2}{*}{ No. } & \multicolumn{3}{|c|}{ KELOMPOK B } \\
\hline & T1 & T2 & $\mathrm{T} 2-\mathrm{T} 1$ & & T1 & T2 & T2 - T1 \\
\hline 1 & 3 & 30 & 27 & 1 & 12 & 35 & 23 \\
\hline 2 & 1 & 10 & 9 & 2 & 3 & 30 & 27 \\
\hline 3 & 4 & 30 & 26 & 3 & 4 & 30 & 26 \\
\hline 4 & 1 & 8 & 7 & 4 & 12 & 35 & 23 \\
\hline 5 & 3 & 9 & 6 & 5 & 4 & 9 & 5 \\
\hline 6 & 4 & 31 & 27 & 6 & 2 & 20 & 18 \\
\hline 7 & 10 & 30 & 20 & 7 & 3 & 9 & 6 \\
\hline 8 & 12 & 30 & 18 & 8 & 12 & 20 & 8 \\
\hline 9 & 3 & 30 & 27 & 9 & 6 & 8 & 2 \\
\hline 10 & 3 & 10 & 7 & 10 & 3 & 20 & 17 \\
\hline 11 & 12 & 30 & 18 & 11 & 4 & 8 & 4 \\
\hline 12 & 6 & 35 & 29 & 12 & 4 & 25 & 21 \\
\hline 13 & 4 & 9 & 5 & 13 & 15 & 40 & 25 \\
\hline 14 & 12 & 40 & 28 & 14 & 1 & 9 & 8 \\
\hline 15 & 1 & 35 & 34 & 15 & 3 & 15 & 12 \\
\hline 16 & 13 & 30 & 17 & 16 & 12 & 45 & 33 \\
\hline 17 & 2 & 8 & 6 & 17 & 1 & 20 & 19 \\
\hline 18 & 15 & 45 & 30 & 18 & 13 & 15 & 2 \\
\hline 19 & 5 & 25 & 20 & 19 & 1 & 20 & 19 \\
\hline 20 & 11 & 30 & 19 & 20 & 4 & 8 & 4 \\
\hline 21 & 4 & 40 & 36 & & & & \\
\hline Jumlah & 129 & 545 & 416 & & 119 & 421 & 302 \\
\hline JK & 1215 & 16951 & 10214 & & 1129 & 11385 & 6326 \\
\hline Rata-rata & 6.14285 & 25.9523 & 19.809 & & 5.95 & 21.05 & 15.1 \\
\hline SD & 4.59658 & 11.8468 & 8.93287 & & 4.70693 & 11.52332 & 8.6403 \\
\hline
\end{tabular}


Tabel Lamp. 2. Data Hasil Pre-test dan Post-test Materi Aljabar

\begin{tabular}{|c|c|c|c|c|c|c|c|}
\hline \multirow{2}{*}{ No. } & \multicolumn{3}{|c|}{ KELOMPOK A } & \multirow{2}{*}{ No. } & \multicolumn{3}{|c|}{ KELOMPOK B } \\
\hline & T1 & T2 & $\mathrm{T} 2$ - T1 & & T1 & T2 & $\mathrm{T} 2$ - T1 \\
\hline 1 & 5 & 39 & 34 & 1 & 10 & 30 & 20 \\
\hline 2 & 0 & 27 & 27 & 2 & 4 & 35 & 31 \\
\hline 3 & 4 & 35 & 31 & 3 & 5 & 31 & 26 \\
\hline 4 & 1 & 10 & 9 & 4 & 11 & 28 & 17 \\
\hline 5 & 3 & 10 & 7 & 5 & 4 & 10 & 6 \\
\hline 6 & 7 & 30 & 23 & 6 & 3 & 17 & 14 \\
\hline 7 & 11 & 35 & 24 & 7 & 3 & 8 & 5 \\
\hline 8 & 15 & 41 & 26 & 8 & 11 & 25 & 14 \\
\hline 9 & 3 & 35 & 32 & 9 & 5 & 12 & 7 \\
\hline 10 & 5 & 12 & 7 & 10 & 3 & 20 & 17 \\
\hline 11 & 11 & 30 & 19 & 11 & 3 & 10 & 7 \\
\hline 12 & 5 & 35 & 30 & 12 & 4 & 20 & 16 \\
\hline 13 & 5 & 10 & 5 & 13 & 14 & 42 & 28 \\
\hline 14 & 6 & 45 & 39 & 14 & 0 & 15 & 15 \\
\hline 15 & 2 & 30 & 28 & 15 & 15 & 20 & 5 \\
\hline 16 & 10 & 35 & 25 & 16 & 11 & 46 & 35 \\
\hline 17 & 5 & 10 & 5 & 17 & 1 & 15 & 14 \\
\hline 18 & 8 & 40 & 32 & 18 & 15 & 20 & 5 \\
\hline 19 & 6 & 25 & 19 & 19 & 2 & 15 & 13 \\
\hline 20 & 15 & 35 & 20 & 20 & 3 & 15 & 12 \\
\hline 21 & 4 & 37 & 33 & & & & \\
\hline Jumlah & 131 & 606 & 475 & & 127 & 434 & 307 \\
\hline JK & 1157 & 20144 & 12945 & & 1257 & 11572 & 6215 \\
\hline Rata-rata & 6.23809 & 28.8571 & 22.6190 & & 6.35 & 21.7 & 15.35 \\
\hline SD & 4.121951 & 11.52513 & 10.4903 & & 4.869616 & 10.64796 & 8.89278 \\
\hline
\end{tabular}


Tabel Lamp. 3. Data Hasil Pre-test dan Post-test Materi Geometri/Trigonometri

\begin{tabular}{|c|c|c|c|c|c|c|c|}
\hline \multirow{2}{*}{ No. } & \multicolumn{3}{|c|}{ KELOMPOK A } & \multirow{2}{*}{ No. } & \multicolumn{3}{|c|}{ KELOMPOK B } \\
\hline & T1 & T2 & $\mathrm{T} 2$ - T1 & & T1 & T2 & T2 - T1 \\
\hline 1 & 1 & 25 & 24 & 1 & 8 & 40 & 32 \\
\hline 2 & 0 & 15 & 15 & 2 & 1 & 25 & 24 \\
\hline 3 & 2 & 30 & 28 & 3 & 3 & 30 & 27 \\
\hline 4 & 2 & 10 & 8 & 4 & 8 & 38 & 30 \\
\hline 5 & 0 & 10 & 10 & 5 & 2 & 15 & 13 \\
\hline 6 & 3 & 25 & 22 & 6 & 0 & 20 & 20 \\
\hline 7 & 6 & 30 & 24 & 7 & 3 & 20 & 17 \\
\hline 8 & 8 & 25 & 17 & 8 & 12 & 20 & 8 \\
\hline 9 & 2 & 20 & 18 & 9 & 5 & 10 & 5 \\
\hline 10 & 2 & 15 & 13 & 10 & 2 & 25 & 23 \\
\hline 11 & 8 & 30 & 22 & 11 & 1 & 5 & 4 \\
\hline 12 & 5 & 30 & 25 & 12 & 2 & 15 & 13 \\
\hline 13 & 1 & 5 & 4 & 13 & 10 & 45 & 35 \\
\hline 14 & 11 & 45 & 34 & 14 & 0 & 5 & 5 \\
\hline 15 & 0 & 30 & 30 & 15 & 2 & 30 & 28 \\
\hline 16 & 11 & 30 & 19 & 16 & 12 & 47 & 35 \\
\hline 17 & 2 & 10 & 8 & 17 & 0 & 18 & 18 \\
\hline 18 & 10 & 40 & 30 & 18 & 10 & 25 & 15 \\
\hline 19 & 3 & 20 & 17 & 19 & 1 & 25 & 24 \\
\hline 20 & 10 & 32 & 22 & 20 & 6 & 20 & 14 \\
\hline 21 & 2 & 42 & 40 & & & & \\
\hline Jumlah & 89 & 519 & 430 & & 88 & 478 & 390 \\
\hline JK & 675 & 15263 & 10470 & & 714 & 14102 & 9470 \\
\hline Rata-rata & 4.23809 & 24.7142 & 20.4761 & & 4.4 & 23.9 & 19.5 \\
\hline SD & 3.85881 & 11.0369 & 9.12479 & & 4.14728 & 11.8716 & 9.90746 \\
\hline
\end{tabular}

